\title{
Spatial S-R compatibility with orthogonal stimulus-response relationship
}

\author{
WALTER H. EHRENSTEIN \\ Institut für Arbeitsphysiologie, Dortmund, West Germany \\ PETER SCHROEDER-HEISTER \\ Universität Konstanz, Konstanz, West Germany \\ and \\ GABRIELE HEISTER \\ Universitätsspital Zürich, Zürich, Switzerland
}

\begin{abstract}
Spatial stimulus-response (S-R) compatibility with unimanual two-finger choice reactions was investigated under conditions in which the spatial orientation of response keys was either parallel to or perpendicular to the orientation of the stimuli. Subjects responded to green or red lights in the left or right visual field (irrelevant stimulus location). The response keys were oriented horizontally on the left or right side of the body midline parallel to the stimuli, and were pressed with the palms facing down (Condition $A$ ), or were oriented orthogonally to the stimuli in the midsaggital plane, either horizontally and pressed with palms facing down (B) or facing up (C), or vertically and pressed with palms facing the body (D). The results for Condition A demonstrate the usual spatial S-R compatibility effect between field of stimulation and spatial position of responding finger. For Conditions $B$ and $D$, a strong reaction time advantage still obtained for those stimulus-finger pairings that are compatible under Condition $\mathrm{A}$. Condition $\mathrm{C}$ revealed an RT advantage for the opposite pairings. This shift of the compatibility effect from Condition $B$ to Condition $\mathrm{C}$ indicates that the left/right distinction of fingers does not follow a simple, fixed spatio-anatomical mapping rule. The results are discussed within the framework of a hierarchical model of spatial S-R compatibility, with spatial coding and spatio-anatomical mapping as factors.
\end{abstract}

Recent results show that effects of spatial stimulusresponse (S-R) compatibility not only obtain with respect to positions of visual stimuli and positions of responding hands, but also with respect to positions of visual stimuli and positions of responding fingers. It has been demonstrated that with unimanual two-finger choice reactions, the spatially right finger responds faster to stimuli in the right than in the left visual field, and the spatially left finger responds faster to stimuli in the left than in the right visual field. This takes place when the responding hand is held in the middle position (Arend \& Wandmacher, 1987; Katz, 1981); to the right or left of the body midline (Heister, Ehrenstein, \& Schroeder-Heister, 1986,

The results reported here were presented in part at the 4th International Conference on Event Perception and Action, Trieste, Italy, August 1987, and at the 1 lth European Conference on Visual Perception, Bristol, England, 1988. We would like to thank Carl R. Cavonius, Stuart T. Klapp, Lester E. Krueger, and an anonymous reviewer for helpful comments and suggestions; Sibylle Marquard and Wilfried Runte for technical assistance; and David Emmans for revising the English. The third author was supported by a research grant from the Deutsche Forschungsgemeinschaft. P. Schroeder-Heister is with the Fachgruppe Philosophie, Universität Konstanz, and G. Heister is with the Abteilung Neuropsychologie, Universitätsspital Zürich. Requests for reprints should be addressed to $W$. H. Ehrenstein, Institut für Arbeitsphysiologie, Ardeystrasse 67, 4600 Dortmund, West Germany.
1987; Ragot \& Lesevre, 1986); crossed, that is, on the opposite side of the body midline (Schroeder-Heister, Ehrenstein, \& Heister, 1988); and in palm-down or palmup position (Heister et al., 1986, 1987). The effects occur when the task requires a spatial decision (relevant stimulus location; see Heister et al., 1986) and when it does not (irrelevant stimulus location- "Simon effect"; see Heister et al., 1987; Heister \& Schroeder-Heister, 1987).

One major theory to explain spatial S-R compatibility is that of spatial coding, which, with respect to bimanual tasks, was first proposed by Wallace (1971) and was further developed by Nicoletti, Anzola, Luppino, Rizzolatti, and Umiltà (1982) for relevant stimulus location and by Umiltà and Nicoletti (1985) for irrelevant stimulus location. According to this hypothesis, the observed effect is due to a comparison of stimulus and response positions as represented in a spatial code, irrespective of anatomical distinctions.

An alternative theory is spatio-anatomical mapping (Heister et al., 1986), which refers to an association between anatomical and spatial distinctions. In the case of bimanual reactions, this means that the right hand is associated as spatially right and the left hand as spatially left, irrespective of the side of the body midline on which the responding hands are held (i.e., irrespective of 
whether or not arms are crossed). In the case of unimanual two-finger choice reactions, we have to define a certain standard hand position with respect to which it is clear which fingers are left or right to each other. Although such a definition is not without problems, for the special task considered here (pressing a button), as well as in everyday activities, the palm-down hand position with the fingers pointing ahead appears to be the most frequent one, and may therefore be assumed to be normal. According to this assumption, the mapping hypothesis states that the middle finger of the right hand and the index finger of the left hand are regarded as spatially right, and the index finger of the right hand and the middle finger of the left hand as spatially left, irrespective of the position of the responding hand (i.e., irrespective of whether palms face up or down or whether response buttons are parallel or orthogonal to the stimulus lights).

The mapping hypothesis is based on the assumption that spatial distinctions that are actually present when the response organs are in a certain normal position are preserved even when the response organs are in unusual positions. In particular, the spatial left/right distinction is assigned to the anatomical distinction between hands or between fingers, even if the arms are crossed or the hands are held in palm-up position. The existing results rule out mapping as the determining factor of spatial S-R compatibility and favor spatial coding: For bimanual choice reactions, crossing the arms does not change the compatibility effect observed with uncrossed arms (Simon, Hinrichs, \& Craft, 1970; Wallace, 1971). Similarly, for unimanual two-finger choice reactions, turning hands to palm-up orientation does not change the compatibility effect observed with palms facing down (Heister et al., $1986,1987)$. In addition, an experiment distinguishing between spatial and anatomical distance of responding fingers showed that the spatial, not the anatomical, distance influenced the compatibility effect (Heister, Schroeder-Heister, \& Ehrenstein, 1988).

However, these results do not mean that spatioanatomical mapping (i.e., assignment of anatomically defined response organs as right or left) does not exist. They simply demonstrate that spatio-anatomical mapping is not dominant when certain spatial cues are present, as in standard experiments of spatial S-R compatibility. It may well be that mapping becomes dominant when spatial cues on the response side are absent.

This is actually predicted by the hierarchical model of spatial S-R compatibility proposed by Heister et al. (1988). According to this model, which is in agreement with many experimental findings (in particular those of Klapp, Greim, Mendicino, \& Koenig, 1979; Ladavas \& Moscovitch, 1984; Riggio, Gawryszewski, \& Umiltà, 1986; Schroeder-Heister, Heister, \& Ehrenstein, in press), spatial S-R compatibility results from several factors, which are rank-ordered in a certain way and whose way of dominating each other or interacting with each other determines the effect observed. In particular, spatial coding, as a factor with higher rank than that of mapping in the hierarchy, is the determining factor if it is applicable, that is, if spatial coding of response effectors is possible along the spatial dimension in which the stimuli are arranged (e.g., left/right). However, if stimulus and response positions cannot be compared in a common spatial code (e.g., if only the stimuli, but not the responses, are arranged along the left/right dimension), spatioanatomical mapping becomes effective.

To test this hypothesis for unimanual two-finger choice reactions, we had subjects respond by pressing buttons mounted along each of the two dimensions that are perpendicular to the left/right dimension of the stimuli. More precisely, in addition to a control condition in which the response buttons were parallel to the stimulus lights (Condition A, see Figure 1), we chose an orthogonal stimulusresponse relationship in which the response buttons were horizontal in the midsaggital plane both for palm-down (Condition B) and palm-up (Condition C) hand positions, and an orthogonal stimulus-response relationship in which the response buttons were vertical in the midsaggital plane (Condition D). In addition to representing one of the two orthogonal S-R relationships, Condition $D$ can also be regarded as intermediate between Conditions $B$ and $C$, since vertical hand position is reached at $90^{\circ}$ when hands are turned from palm-down position $\left(0^{\circ}\right)$ to palm-up po-

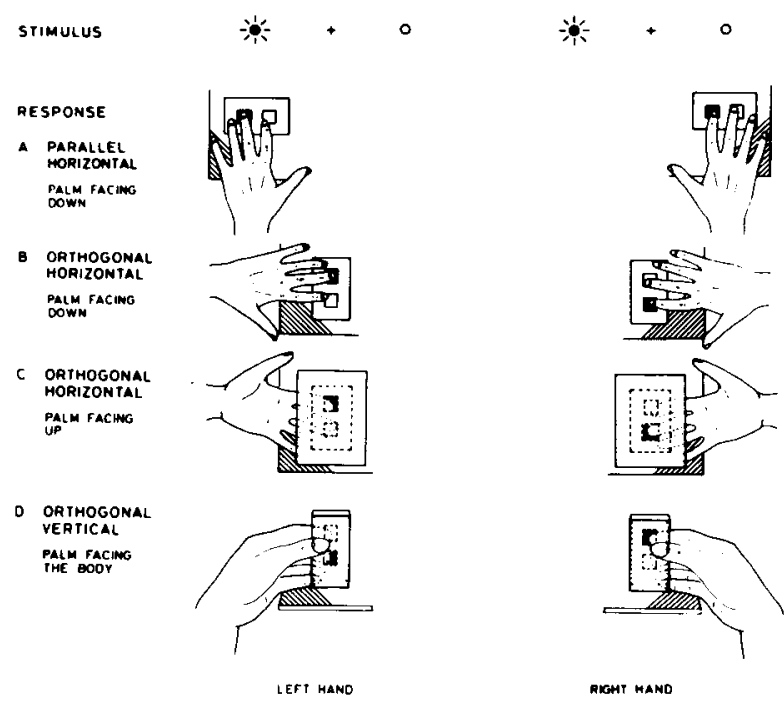

Figure 1. Schematic representation of the stimulus-response arrangements for experimental Conditions $A$ to $D$. The examples shown are for the left hand and the right hand, both responding to a stimulus that appears to the left of fixation. In Condition $A$ (control) the response keys are horizontal on the left or right side of the body midline, parallel to the left/right stimulus orientation. In Conditions $B$ and $C$ the response keys are horizontal and orthogonal to the stimulus orientation in the midsaggital plane, pressed with the palm facing down (B) or facing up (C). In Condition D the response keys are vertical and orthogonal to the stimulus orientation in the midsaggital plane, pressed with the palm facing the body. (In A, $B$, and $C$ the viewing direction of this schematic representation is vertical downward, whereas in $D$ it is nearly horizontal.) Response keys depicted as black denote that finger-stimulus pairing that yields a shorter reaction time. 
sition $\left(180^{\circ}\right)$. If the model described above is true, for Conditions B, C, and D an effect of spatio-anatomical mapping should be observed corresponding to the compatibility effect to be expected for Condition A.

\section{METHOD}

\section{Subjects}

Eight college or university students ( 4 male, 4 female; aged 19-26 years) served as paid subjects. They all were right-handed according to a German adaptation of the Edinburgh Inventory (Oldfield, 1971), had normal color vision, and had no special training in visual reaction tasks. All subjects served in each of the four experimental conditions and were naive as to the purpose of the task.

\section{Apparatus}

The subjects sat in front of a modified Förster Perimeter (OCULUS). Head position was fixed by a forehead/chinrest, and the distance between the eyes and the perimeter plane was $45 \mathrm{~cm}$. Two shielded lamps provided a dim and diffuse ambient illumination. Two bicolor (red/green) light-emitting diodes (LEDs; TELEFUNKEN CQX 95) produced circular lights of 560-nm and 630nm peak wavelengths subtending $38^{\prime}$ of arc. The center of the stimuli was positioned at $5^{\circ}$ of visual angle to the left and right of the fixation point. The fixation point consisted of a white circular field subtending a visual angle of $0.75^{\circ}$ on a gray perimeter plane. Luminance (measured by a HAGNER Universal Photometer S2) was $2.5 \mathrm{~cd} / \mathrm{m}^{2}$ for the perimeter background, was $4.1 \mathrm{~cd} / \mathrm{m}^{2}$ for the fixation point, and ranged between 170 and $185 \mathrm{~cd} / \mathrm{m}^{2}$ for the LEDs. The subject's ability to maintain fixation properly was tested in a number of pretrials in which eye movements were monitored by an infrared photoelectric device displayed on an oscilloscope. The stimuli were presented for $100 \mathrm{msec}$ following an acoustic warning that preceded the stimulus onset randomly by 500 to $800 \mathrm{msec}$. The response keys were two microswitches (SCHADOW-digitast SE, with electronic rebound suppression) of a microswitch box, connected to an electronic clock that was started with the stimulus onset and stopped by the microswitch contact. The centers of the keys were $30 \mathrm{~mm}$ apart. The microswitch box was freely movable and was attached in four positions according to the requirements of each condition (see Figure 1). Condition A, the control condition, was a replication of Condition 1 of Heister et al. (1987); the response keys were positioned in the horizontal dimension parallel to the stimuli at the left or right side of the experimental desk. In Conditions $\mathrm{B}, \mathrm{C}$, and $\mathrm{D}$, the response keys were placed orthogonally to the stimuli in middle position. In Condition B, they were placed in the horizontal dimension (palm-down hand position). In Condition $C$, the microswitch box was mounted underneath a shelf placed horizontally on the desk, allowing the hands to press the key from below (palm-up hand position). In Condition D, the response keys were arranged in the vertical dimension, with the palm of the responding hand facing the body.

\section{Procedure}

The subjects attended four sessions on different days. Each session was subdivided into four blocks separated by short rest periods. Each block consisted of 6 practice trials and 44 test trials, with 11 stimulus presentations for each of the four combinations of color and visual field (red/left field, red/right field, green/left field, and green/right field). Stimuli were presented in a particular quasirandom order within each block, allowing a maximum of only three consecutive stimuli of the same color or in the same field.

The subjects had to press one of the two microswitches with either their index or middle finger as fast as possible while maintaining their gaze on the fixation point. In two blocks of each session the subjects made right finger responses to red lights and left finger responses to green lights, and in the other two blocks they made left finger responses to red lights and right finger responses to green lights. The order of blocks within each session was balanced across subjects. The responding hand (left or right) was altered from one block to the next. For each block, the subjects were told to use the appropriate finger (index or middle), in order not to draw their attention to spatial relationships. Two subjects started with Condition A, 2 with Condition B, 2 with Condition C, and 2 with Condition D. Errors were few (about $1 \%$ ), and error trials were repeated at the end of each block.

\section{RESULTS}

Medians of the reaction times (RTs) were subjected to a four-way $(4 \times 2 \times 2 \times 2)$ within-subjects analysis of variance (ANOVA) with the following factors: experimental condition (A to D), field of stimulus presentation (left or right), responding hand (left or right), and responding finger (left or right). Fingers were classified as left or right according to their spatial position with palm-down hand orientation (i.e., middle finger $=$ left and index finger $=$ right for the left hand, and index finger $=$ left and middle finger = right for the right hand). In this paper, compatibility or incompatibility of field-finger relationships is understood with respect to this classification. Cell means and standard deviations are given in Table 1.

A significant main effect for field of stimulation was obtained $[F(1,7)=10.78, p<.05]$, meaning that overall responses were $9 \mathrm{msec}$ faster with left-field than with right-field stimulation. The significant interaction between hand and finger $[F(1,7)=9.74, p<.05]$ indicates a superiority for index fingers (right finger of the left hand and left finger of the right hand), which responded $18 \mathrm{msec}$ faster than middle fingers (left finger of the left hand and right finger of the right hand). The interaction between field of stimulation and responding hand, which would express a spatial S-R compatibility effect for hands, was far from being significant $[F(1,7)=.38]$. Of greater importance is the significant interaction between field of stimulation and responding finger $[F(1,7)=88.69$, $p<.001]$, which reflects a strong spatial S-R compatibility effect for fingers. Compatible responses were faster by $27 \mathrm{msec}$ than incompatible ones. However, means show that this compatibility effect obtained in Condition A (where it was $54 \mathrm{msec}$ ), Condition B (41 msec), and Condition $D(42 \mathrm{msec})$, but not in Condition $C$ where incompatible reactions were faster by $28 \mathrm{msec}$ than compatible ones (see Table 1). This is confirmed by the significant interaction between experiment, field of stimulation, and responding finger $[F(3,21)=30.95, p<.001$; multivariate Hotelling $\left.T^{2}: F(3,5)=25.66, p<.01\right]$. No other main effects or interactions proved significant.

In a four-way subanalysis $(3 \times 2 \times 2 \times 2)$ which compared Conditions $\mathrm{A}, \mathrm{B}$, and $\mathrm{D}$, the interaction between experimental condition, field of stimulation, and responding finger did not approach significance. This confirms that the three-way interaction of the grand ANOVA is due to the reversal of the compatibility effect in Condition $\mathrm{C}$, and not to a significant difference in the size of 
Table 1

Means of the Median Reaction Times (in msec) and Standard Deviations

\begin{tabular}{|c|c|c|c|c|c|c|c|c|}
\hline & \multicolumn{4}{|c|}{ Left Light } & \multicolumn{4}{|c|}{ Right Light } \\
\hline & \multicolumn{2}{|c|}{ Left Hand } & \multicolumn{2}{|c|}{ Right Hand } & \multicolumn{2}{|c|}{ Left Hand } & \multicolumn{2}{|c|}{ Right Hand } \\
\hline & $\begin{array}{c}\text { Left } \\
\text { Finger } \\
\text { (Middle) }\end{array}$ & $\begin{array}{l}\text { Right } \\
\text { Finger } \\
\text { (Index) }\end{array}$ & $\begin{array}{c}\text { Left } \\
\text { Finger } \\
\text { (Index) }\end{array}$ & $\begin{array}{l}\text { Right } \\
\text { Finger } \\
\text { (Middle) }\end{array}$ & $\begin{array}{c}\text { Left } \\
\text { Finger } \\
\text { (Middle) }\end{array}$ & $\begin{array}{l}\text { Right } \\
\text { Finger } \\
\text { (Index) }\end{array}$ & $\begin{array}{c}\text { Left } \\
\text { Finger } \\
\text { (Index) }\end{array}$ & $\begin{array}{c}\text { Right } \\
\text { Finger } \\
\text { (Middle) }\end{array}$ \\
\hline \multicolumn{9}{|c|}{ Condition A (Parallel Horizontal Palm Down) } \\
\hline $\begin{array}{l}M \\
S D\end{array}$ & $\begin{array}{r}341 \\
20\end{array}$ & $\begin{array}{r}383 \\
22\end{array}$ & $\begin{array}{r}316 \\
17\end{array}$ & $\begin{array}{r}386 \\
39\end{array}$ & $\begin{array}{r}404 \\
42\end{array}$ & $\begin{array}{r}322 \\
20\end{array}$ & $\begin{array}{r}360 \\
30\end{array}$ & $\begin{array}{r}336 \\
30\end{array}$ \\
\hline \multicolumn{9}{|c|}{ Condition B (Orthogonal Horizontal Palm Down) } \\
\hline $\begin{array}{l}M \\
S D\end{array}$ & $\begin{array}{r}325 \\
39\end{array}$ & $\begin{array}{r}361 \\
57\end{array}$ & $\begin{array}{r}314 \\
44\end{array}$ & $\begin{array}{r}366 \\
72\end{array}$ & $\begin{array}{r}373 \\
43\end{array}$ & $\begin{array}{r}322 \\
25\end{array}$ & $\begin{array}{r}372 \\
39\end{array}$ & $\begin{array}{r}348 \\
46\end{array}$ \\
\hline \multicolumn{9}{|c|}{ Condition C (Orthogonal Horizontal Palm Up) } \\
\hline $\begin{array}{l}M \\
S D\end{array}$ & $\begin{array}{r}385 \\
41\end{array}$ & $\begin{array}{r}352 \\
44\end{array}$ & $\begin{array}{r}358 \\
51\end{array}$ & $\begin{array}{r}357 \\
47\end{array}$ & $\begin{array}{r}373 \\
41\end{array}$ & $\begin{array}{r}387 \\
41\end{array}$ & $\begin{array}{r}348 \\
30\end{array}$ & $\begin{array}{r}412 \\
53\end{array}$ \\
\hline \multicolumn{9}{|c|}{ Condition D (Orthogonal Vertical Palm Facing the Body) } \\
\hline $\begin{array}{l}M \\
S D\end{array}$ & $\begin{array}{r}327 \\
47\end{array}$ & $\begin{array}{r}346 \\
41\end{array}$ & $\begin{array}{r}312 \\
26\end{array}$ & $\begin{array}{r}383 \\
48\end{array}$ & $\begin{array}{r}374 \\
65\end{array}$ & $\begin{array}{r}323 \\
44\end{array}$ & $\begin{array}{r}370 \\
38\end{array}$ & $\begin{array}{r}342 \\
39\end{array}$ \\
\hline
\end{tabular}

Note-Fingers are classified as "left" or "right" according to their spatial position when palms face down.

the compatibility effect between Conditions A, B, and D. Separate subanalyses for each of the four experimental conditions demonstrated that the compatibility effect or its reversal (in Condition C) was present in all cases [interaction between field of stimulation and responding finger for Condition A: $F(1,7)=47.09, p<.01$; Condition B: $F(1,7)=39.46, p<.01$; Condition C: $F(1,7)$ $=30.58, p<.01$; Condition $\mathrm{D}: F(1,7)=45.87$, $p<.01]$. Inspection of the individual data revealed that these results are independent of the order of conditions. All subjects showed the compatibility effect in Conditions $\mathrm{A}, \mathrm{B}$, and $\mathrm{D}$, and its reversal in Condition $\mathrm{C}$.

\section{DISCUSSION}

The main hypothesis tested by this study was that spatioanatomical mapping (i.e., the association of response effectors as left or right) becomes effective when spatial coding of the effectors' positions as left or right is not applicable. According to this hypothesis, which is part of the hierarchical model of spatial S-R compatibility (Heister et al., 1988), RT advantages for certain stimulusresponse pairings are still obtained when the spatial (left/right) cues of the response are eliminated, since left/right distinctions are mapped onto the response effectors. This model views spatial coding as a factor that dominates mapping in the case where coding is possible, but that is replaced by mapping when spatial codes cannot be used (see also Klapp et al., 1979).

This model is supported by our results insofar as highly significant $R T$ advantages for certain S-R pairings are obtained not only in the control condition (Condition A), but also under Conditions B, C, and D, where no spatial (left/right) cues of the response position are present. Under Condition A (which replicates Condition 1 of Heister et al., 1987), a normal compatibility effect was obtained: the spatially right finger (middle finger of the right hand, index finger of the left hand) was faster to lights in the right than in the left visual field, and the spatially left finger (index finger of the right hand, middle finger of the left hand) was faster to lights in the left than in the right visual field. If one assumes a mapping of these spatial positions to the anatomical fingers, the results of Conditions $B$ and $D$ (orthogonal horizontal response position with palms facing down, and orthogonal vertical response position) show a clear-cut mapping effect, that is, for right-hand responses an $\mathrm{RT}$ advantage for the middle finger/right light and index finger/left light relations, and for left-hand responses an RT advantage for the index finger/right light and middle finger/left light relations.

However, the results for Condition $\mathrm{C}$ with response keys orthogonal to the stimuli and horizontal, and with hands held palms up, show a converse result, that is, for right-hand responses an RT advantage for the index finger/right light and middle finger/left light relations, and for left-hand responses an RT advantage for the middle finger/right light and index finger/left light relations. This corresponds to the spatial compatibility effect found for palm-up (but parallel) hand position in Heister et al. (1987, Condition 2). In general, the pattern of results for the orthogonal Conditions B, C, and D can be described as follows: The results in Conditions $\mathrm{B}$ and $\mathrm{D}$ correspond to what would be obtained as spatial compatibility effects after turning the hands into palm-down parallel positions (as in Condition A), and the results in Condition C correspond to what would be obtained after turning the hands into palm-up parallel position.

For this result to be interpreted as an effect of spatioanatomical mapping, the only possibility is to develop a more sophisticated notion of mapping, according to which the association of spatial positions to fingers of one hand depends on whether the palms face down or up: In palm- 
down position one follows the simple concept of mapping described in the introduction (middle finger = right, index finger $=$ left for the right hand, and the converse for the left hand), whereas in palm-up position this association is inverted (i.e., index finger $=$ right, middle finger $=$ left for the right hand, and the converse for the left hand).

This modified concept of mapping may be justified as follows. The idea of an association of spatial distinctions with anatomical left/right distinctions crucially assumes that there is a "normal" position, in which anatomically defined organs are in a certain spatial relationship. This position is then associated with these organs even if they are in a "non-normal" position. For the (anatomically) left and right hands, this is obvious: it is normal to hold them on the (spatially) left or right side of the body, respectively. For fingers of one hand, this is not so obvious. The association of the index finger with the left and the middle finger with the right for two-finger choice reactions of the right hand and the converse for the left hand hinges on the assumption that palm-down hand position is normal and the palm-up hand position is not. If this specific normality assumption is dropped and both palmdown and palm-up positions are considered equally normal, one is led to the more elaborated concept of mapping as described above.

Another approach to explain the pattern of results of Conditions $\mathrm{B}$ and $\mathrm{C}$ is to consider the wrist to be the spatial reference point for the left/right distinction of finger responses. " Obviously, this left/right distinction with respect to the wrist does not depend on whether the hand is held palm-down or palm-up. However, "right" and "left" with respect to the wrist cannot be defined without assuming a normal hand position, with respect to which it is clear what right and left mean. This reference to a normal position (which would again have to be a horizontal parallel position) is in this case treated as a case of spatio-anatomical mapping, so that this approach is covered by our modified mapping hypothesis.

The results for Condition D (response buttons orthogonal to the stimuli and vertical) correspond to those in Conditions A and B and not to those in Condition C (see Table 1). Since Condition D involves an intermediate hand position between those of Conditions B and C (hand turned only by $90^{\circ}$ and not yet by $180^{\circ}$ as in Condition $\mathrm{C}$ ), one might hypothesize that its results are intermediate between those of Conditions B and C: The compatibility effect of Condition B should disappear under Condition D and reverse under Condition C. The result actually obtained shows that the vertical hand position, with the palms facing the body, is more similar to the palm-down position than to the palm-up position. In other words, it seems to be the palm-up condition that is distinguished, whereas vertical hand positions are internally represented like the corresponding palm-down positions. This result confirms the effectiveness of spatioanatomical mapping and therefore supports the hierarchi- cal model of S-R compatibility, since for vertical response positions the absence of spatial right/left cues is even more obvious than for the horizontal positions with orthogonal S-R relationship.

It is not possible to explain our results in Conditions B, $C$, and $D$ by reference to a compatibility between the left/right stimulus orientation and a farther/nearer (Conditions B and C) or top/down (Condition D) response orientation. As displayed in Figure 1, the reaction time advantages for the farther/nearer and top/down dimensions are opposite for the left and right hands, since they are rotated clockwise and counterclockwise, respectively, when turned to a middle position.

The absence of any compatibility effect with respect to the relationship between field of stimulus presentation and responding hand (in addition to the compatibility effects obtained for the responding fingers) is in agreement with our previous findings and explanations (see Heister et al., 1986,1987 ), as is the general superiority of the index fingers over the middle fingers. The overall left-field superiority again supports the hypothesis of a lateralization of color discrimination to the right hemisphere (Pennal, 1977; for review see Davidoff, 1982), which was also used to explain the data of Heister et al. (1987).

In conclusion, our data demonstrate that effects of spatial S-R compatibility with unimanual two-finger choice reactions also obtain for different orthogonal stimulusresponse relationships, stressing the importance of hand orientation (palm up vs. palm down) for the direction of the observed effect. These results are in accordance with the predictions of the hierarchical model of spatial S-R compatibility using a modified concept of spatioanatomical mapping. A comprehensive explanation of spatial $S-R$ relationships thus affords a theory based on the integration of various factors including coding and mapping.

\section{REFERENCES}

Arend, U., W Wandmacher, J. (1987). On the generality of logical recoding in spatial interference tasks. Acta Psychologica, 65, 193-210.

DA vidoff, J. (1982). Studies with non-verbal stimuli. In J. G. Beaumont (Ed.), Divided visual field studies of cerebral organization (pp. 29-55), London: Academic Press.

Heister, G., Ehrenstein, W. H., \& Schroeder-Heister, P. (1986). Spatial S-R compatibility effects with unimanual two-finger choice reactions for prone and supine hand positions. Perception \& Psychophysics, 40, 271-278.

Heister, G., Ehrenstein, W. H., \& Schroeder-Heister, P. (1987). Spatial S-R compatibility with unimanual two-finger choice reactions: Effects of irrelevant stimulus location. Perception \& Psychophysics, 42, 195-201.

HeIsTer, G, \& SChroeder-HeIster, P. (1987). Evidence for stimulus-response compatibility effects in a divided visual field study of cerebral lateralization. Acta Psychologica, 66, 127-138.

Heister, G., Schroeder-Heister, P., Ehrenstein, W.H. (1988). Spatial coding and spatio-anatomical mapping: A hierarchical model of spatial S-R compatibility. In R. W. Proctor \& T. G. Reeve (Eds.), Stimulus-response compatibility: An integrated perspective. Amsterdam: North-Holland.

KATZ, A. N. (1981). Spatial compatibility effects with hemifield presen- 
tation in a unimanual two-finger task. Canadian Joumal of Psychology, 35, 63-68.

Klapp, S. T., Greim, D. M., Mendicino, C. M., Koenig, R. S. (1979). Anatomic and environmental dimensions of stimulus-response compatibility: Implication for theories of memory coding. Acta Psychologica, 43, 367-379.

Ladavas, E., Moscovitch, M. (1984). Must egocentric and environmental frames of reference be aligned to produce spatial S-R compatibility effects? Journal of Experimental Psychology: Human Perception \& Performance, 10, 205-215.

Nicoletti, R., Anzola, G. P., Luppino, G., Rizzolatti, G., \& Umilti, C. (1982). Spatial compatibility effects on the same side of the body midline. Journal of Experimental Psychology: Human Perception \& Performance, 8, 664-673.

OLDFIELD, R. C. (1971). The assessment and analyses of handedness: The Edinburgh Inventory. Neuropsychologia, 9, 97-113.

Pennal, B. E. (1977). Human cerebral asymmetry in color discrimination. Neuropsychologia, 15, 563-568.

RAGOT, R., \&ESEVRE, N. (1986). Electrophysiological study of intrahemispheric S-R compatibility effects elicited by visual directional cues. Psychophysiology, 23, 19-27.

Riggio, L., GAwryszewski, L. G., \& UmiltA, C. (1986). What is crossed in crossed-hand effects? Acta Psychologica, 62, 89-100.
Schroeder-Heister, P., Ehrenstein, W. H., \& Heister, G. (1988). Spatial $S$-R compatibility effects for hands and fingers with unimanual two-finger choice reactions. Manuscript in preparation.

Schroeder-Heister, P., Heister, G., \& Ehrenstein, W. H. (in press). Spatial S-R compatibility under head tilt. Acta Psychologica.

Simon, J. R., Hinrichs, J. V., \& Craft, J. L. (1970). Auditory S-R compatibility: Reaction time as a function of ear-hand correspondence and ear-response-location correspondence. Joumal of Experimental Psychology, 86, 97-102.

Umilti, C., Nicoletti, R. (1985). Attention and coding effects in S-R compatibility due to irrelevant spatial cues. In $\mathbf{M}$. I. Posner, \& O. S. M. Marin (Eds.), Attention and performance XI (pp. 457-471). Hillsdale, NJ: Erlbaum.

WALLACE, R. J. (1971). S-R compatibility and the idea of a response code. Journal of Experimental Psychology, 88, 354-360.

\section{NOTE}

1. This possibility was brought to our attention by L. Krueger.

(Manuscript received March 11, 1988; revision accepted for publication August 24,1988 .) 